\title{
Educados, ¿para qué?
}

Jaime Araujo Frías ${ }^{1}$

jaraujofrias@gmail.com

Universidad Nacional de San Agustín/Perú

\section{Resumen}

Las instituciones como la educación, son mediaciones para la vida. Sin embargo, hoy estamos siendo educados, no para afirmar la vida humana, sino para afirmar y reproducir el aumento de la tasa de ganancia. No el crecimiento y desarrollo de la vida humana y de las condiciones que la posibilitan, sino el crecimiento económico en detrimento de las dos únicas fuentes de vida: el trabajo humano y la naturaleza. Por tal razón, urge una reflexión crítica sobre la educación a efectos de enderezar esta perniciosa inversión.

Palabras clave: Filosofía, pensar, crítica, vida, educación.

\begin{abstract}
The institutions as education are means for life. Nevertheless, today we are being educated, not for asserting human life but for asserting and reproducing the rising of profit rate, of capital. Not the rising and development of human life and the conditions that make it possible but the economic growth, harming the only two sources of life: human labor and nature. For that reason, we need a critical reflection over education and for the purposes of straightening such harmful inversion.
\end{abstract}

Keywords: Philosophy, thinking, criticism, life, education.

\footnotetext{
${ }^{1}$ Filósofo y Abogado. Director del Centro de Estudios Disenso. Maestrando en Derecho Constitucional en la
} Universidad Nacional Mayor de San Marcos. 
«El mundo al revés nos enseña a padecer la realidad en lugar de cambiarla, a olvidar el pasado en lugar de escucharlo y a aceptar el futuro en lugar de imaginarlo. En la escuela son obligatorias las clases de impotencia, amnesia y resignación.»

Eduardo Galeano

En plena época del mundo al revés, pareciera que no hay nada que hacer más que soportar. La excepción se ha vuelto regla y la regla excepción, el medio fin y el fin medio, el sujeto cosa y la cosa sujeto, la injusticia justicia y la justicia injusticia. En otras palabras, como advierte Hinkelammert (2010), lo primero, la vida humana, se ha vuelto secundario, y lo secundario, las instituciones, sobre todo del mercado, lo primero. Es en este contexto en el que intentamos pensar la educación, porque esta también ha sido infestada por este modo de concebir el mundo, por lo tanto, de lo que se trata es de investigar para sacar a la luz las consecuencias perniciosas de esta inversión para negarlo e imaginar una educación pertinente a la afirmación de la vida, único criterio de verdad práctica universal.

\section{Pensar es pensar en situación}

Pensamos que se debe investigar sobre los problemas que interesan a nuestros pueblos y, sobre todo, a los pueblos más vulnerables, que en nuestro margen hispanoamericano son las grandes mayorías. Son ellos, la exterioridad, para usar una categoría de la filosofía de la liberación, el lugar epistemológico desde donde intentamos pensar o, mejor dicho, sentipensar la educación.

Todo pensar es un pensar en situación, es decir, tiene un punto de partida, pero también tiene criterios que le orientan hacia fines concretos. ¿Cómo pensar neutralmente cuando la vida de nuestros pueblos es negada para hacer crecer el capital? O pensamos para negar esta lógica o pensamos para afirmarlo. No es posible poner en cuestión las instituciones que producen sufrimiento e injusticia y los saberes que la avalan si no pensamos desde una determinada situación. Es decir, no podemos ser neutrales, la neutralidad —en el mejor de los casos - es una broma y, en el peor, una aberración intelectual

El filósofo si es crítico no piensa: la filosofía no piensa textos filosóficos, y si lo hace es solo como pretexto para pensar de mejor modo aquello que debe pensar: la realidad (Dussel, 2012). Hoy es imperativo que lo haga pero, no cualquier realidad, sino la realidad problemática, pero no cualquier realidad problemática, acaso prioritariamente aquellos problemas que afectan, en principio, la vida humana en general y, preferencialmente, la vida 
de los seres humanos más victimados por la forma actual de organizar las instituciones sociales.

No obstante, llevar a cabo esta tarea exige entrar en disenso, en desacuerdo con el modo de gestionar las instituciones sociales, entre ellas la educación actual materia del presente ensayo. La misma que se ha convertido en mediación para el aumento de la tasa de ganancia, del lucro a costa de la vida humana y de la naturaleza. Los programas educativos, salvo algunas excepciones, están diseñados para evitar toda forma de pensamiento disidente al estado de cosas actuales. Conciben al alumno como una especie de recipiente vacío, que hay que llenar de contenidos funcionales al aumento del capital. Es decir, anular toda disposición a pensar... y a pensar de manera crítica.

\section{Educados para no pensar}

El pensamiento fraguado en la lógica de las relaciones sociales vigentes, es decir, el pensamiento forjado con el criterio de que el dinero es nuestro destino es pura repetición. Por eso, no se educa para pensar, sino para repetir los contenidos pertinentes para hacer funcionar la maquinaria del mercado. En este raciocinio, un buen alumno es aquel que cuenta con dos requisitos específicos: gran memoria y nulo pensamiento crítico o creativo.

Para el modo actual de organizar y gestionar la sociedad el pensamiento crítico, disidente es un estorbo. Porque pensar de modo crítico significa penetrar en la realidad, pasar del mundo del aparecer a aquello que ha sido encubierto, y que es el fundamento y condición de posibilidad de toda praxis humana: la vida. Para el orden vigente la excepción se ha convertido regla y la regla excepción; el medio fin y el fin medio; el sujeto cosa y la cosa sujeto. Esta inversión consiste, en último término, en creer que sin dinero somos nada cuando en realidad es que sin creatividad humana y sin naturaleza somos nada. Por eso, es urgente la crítica: para poner de pie lo que ha sido puesto de cabeza.

Las instituciones - como la educación-, no son fines en sí mismas, sino mediaciones para la vida. Sin embargo, hoy estamos siendo educados no para afirmar la vida humana, sino para afirmar y reproducir el aumento de la tasa de ganancia: el capital. No el crecimiento y desarrollo de la vida humana y de las condiciones que la posibilitan, sino el crecimiento económico en base a la destrucción de las dos únicas fuentes de vida: el trabajo humano y la naturaleza.

\section{La vida humana como criterio de verdad del pensamiento crítico}

El pensamiento crítico es imprescindible si se quiere abrir grietas para irrumpir en lo no pensado, en lo no sabido o en lo encubierto. Imaginar una educación distinta a la actual, pero no por avidez de novedad, sino por necesidad, exige problematizar, cuestionar y criticar su patología para negarlo. Porque cuando irradia la barbarie, la crítica se torna en una urgencia de vida o muerte: la historia humana es la historia de la crítica. Por eso, hoy vivimos el dilema de educar para formar empleados funcionales al aumento de la tasa de ganancia o educar para 
formar profesionales con miras a jugarse por afirmar la vida humana. Es decir, educar para legitimar el estado de cosas actuales o educar para criticarla y buscar posibles salidas.

Estamos pues, en una situación apremiante para el pensamiento crítico, porque hoy más que nunca necesitamos que las cosas sean diferentes a las vigentes. Necesitamos producir un nuevo pensamiento que nazca de la necesidad histórica social de nuestros pueblos, quienes por siglos han sufrido la postergación, la opresión y la injusticia cómplice de una educación conforme al desarrollo del capital y no conforme al desarrollo de la vida.

Hoy la vida humana está en peligro. Se ha puesto en competencia la vida con el dinero. Y al parecer Mammon (dios del dinero) está ganando. Si esto es así, la única competencia que vale la pena correr hoy es la competencia de la vida contra la muerte. Por eso, para nosotros la afirmación de la vida humana es el criterio de verdad de todo pensamiento crítico (Hinkelammert, 2007). En otras palabras, el desarrollo y aumento de la producción y reproducción de la vida humana comunitaria debe ser el fin de una educación crítica, que no es otra cosa que una educación para la vida.

Una educación que luche contra todo aquello que se oponga a que «el ser humano sea el ser supremo para el ser humano» (Fromm, 1970: 230). Es decir, contra toda relación social que haga del ser humano una mercancía, un medio para lucrar. O, para decirlo de otro modo, nuestro método crítico consiste en «situarnos en el lugar de las víctimas y desde allí efectuar un diagnóstico de la patología» (Dussel, 2006: 140); de la educación vigente para negarlo. Las instituciones son históricas y, por tanto, falibles. Por eso, cuando una institución niega la vida hay que tener la valentía de intervenirla para corregirlo.

Propugnamos este punto de vista porque pensamos que «el fin de toda actividad humana es poder vivir» (Fichte en: Dussel, 2007: 376); por tanto, la razón está al servicio de este fin. Mejor dicho, en última instancia no vivimos para pensar, argumentar o criticar, sino que pensamos y argumentamos para vivir. El fundamento de la razón es la vida. Porque para que haya razón es necesario el cerebro y para que haya un cerebro capaz de pensar y ser sensible a los problemas más urgentes: debe estar vivo.

Entonces, la voluntad de vivir es condición de posibilidad de todo saber e institución. Lo primero en la vida del ser humano no es la economía, el derecho, la ciencia o la filosofía. No son el saber o conocer como fines en sí mismos. Es la conservación de la vida misma la que hace posible el querer conocer, saber o el crear instituciones: la cultura es mediación para desarrollar la vida y no mediación para desarrollar el capital a costa de la vida humana.

En resumen, para decirlo con Dussel (2001: 119), «la vida humana es el criterio de verdad práctica universal». Por ello, ningún saber, ningún acto, micro o macro institución o todo un sistema puede dejar de tener como contenido concreto a la misma vida humana. Porque en 
última instancia ¿para qué piensa, crea instituciones o cultura el ser humano, si no es para ampliar su vida, para seguir viviendo y no perecer prematuramente en el camino?

\section{¿Para qué educar?}

Educar no solamente significa trasmitir conocimientos es, sobre todo, generar las condiciones para que el otro a partir de dichos conocimientos pueda expresar lo mejor que tiene. Eso se llama crear, y crear significa capacidad para pensar y generar ideas nuevas. Pero no cualquier idea, sino aquella pertinente a la afirmación y desarrollo de la vida humana. Porque crear tiene que ver con la capacidad para desarrollar la vida. En otras palabras: educar es, sobre todo, enseñar a pensar en función de la vida humana. Entonces, ¿para qué pensar en tiempos del culto al dios dinero y el desprecio por la vida humana?

Concebimos el pensar no como un fin en sí mismo, no como un lujo cultural, no como un pasatiempo; sino como un arma de defensa, de debate y rebate contra todas las fuerzas que niegan la vida humana y las condiciones que la posibilitan. Tarea que en rigor requiere criterios de evaluación de nuestros juicios acerca del contenido de lo que pensamos, de otro modo ¿qué sentido tiene educar para pensar?

Una de las ciencias más avanzadas actualmente: la neurociencia, sostiene que la función básica del órgano productor de pensamiento: el cerebro, es la afirmación de la vida (Mora, 2002; Rubia, 2006). Es decir, el cerebro funciona a partir del criterio vida-muerte. Por tanto, apoyados en esta hipótesis podemos decir, que la defensa de la vida es el contenido material del pensar y, como enseña Dussel (2001), el único criterio práctico de verdad universal. Por ello, pensar no es un lujo, argumentar no es una pompa; en nuestro país, como en muchos, pensar y argumentar contra las fuerzas que niegan los medios de vida, es una necesidad urgente.

Así pues, si pensar «es hacer retroceder a la muerte, es dilatar el espacio de la vida» (Saramago en: Gómez Aguilera, 2010: 106). Lo primero en la vida del ser humano — por sentido común - , no es la filosofía, no es la ciencia, no es el derecho, tampoco la economía; en síntesis, no es el aumento del capital — primer y único criterio de la educación conforme al mercado-. Lo primero es el aumento de la tasa de vida, mejor dicho, el acceso a los medios que posibilitan la vida humana.

La crítica de la educación que hacemos no tiene por objeto la crítica como fin en sí misma, sino la crítica de las relaciones sociales fundadas en el criterio de que el dinero es lo que cuenta, para dar lugar a un nuevo tipo de relación social de producción y de consumo basada en el razonamiento de que es la afirmación de la vida humana y de la naturaleza la que cuenta en última instancia. Por lo que, siguiendo a Nussbaum (2010), resulta peligroso, puesto que la educación actual, salvo algunas excepciones, lo que pretende es tener personas obedientes con capacitación técnica que lleve a la práctica los planes de las élites dominantes. Es decir, 
personas que renuncien a pensar. Por eso, en general se educa no para pensar, sino para repetir lo que otros han pensado.

\section{Epílogo}

El epílogo es lo que se agrega sobre lo ya dicho, es decir, sobre las razones ya expuestas. La expresión griega logos, normalmente se la ha traducido como razón, en realidad quiere decir palabra y razón, porque no existen razones independientes de la palabra. Las razones se dicen, se expresan, es decir, se hablan y se comunican (Bautista Segales, 2005). Hay que pensar pero, mucho más, hay que decir lo que pensamos, y ello conlleva el riesgo de ser vilipendiados, sin embargo, también a veces, de ser elogiados.

Las razones expuestas en el presente ensayo aspiran más: a ser pensadas, discutidas y, si es posible, debatidas y rebatidas, para que la razón — que en nuestra opinión es un medio al servicio de la afirmación de la vida-, discurra; porque si no hay discusión, el pensamiento se petrifica, muere. No obstante, para que las razones sean susceptibles de ser pensadas y discutidas es necesario que sean entendibles. La claridad no es la cortesía del que escribe, como enseñaba Ortega y Gasset. Si se trata de pensar, de razonar y vestirlas con las alas del lenguaje para arrojarlas al mundo, al juicio de los otros; la claridad se torna en una necesidad vital. Porque como dice Benveniste (en Marina y De la Valgona, 2007: 23): «Mucho antes de servir para comunicar, el lenguaje sirve para vivir.»

Y si no hemos sido claros respecto del problema objeto de reflexión - porque en todo lo que se dice, siempre queda algo por decirse - valga la siguiente tesis: hoy es urgente una educación que promueva un mirar, sentir, pensar y hacer en el mundo desde la perspectiva que ponga la vida humana, mejor dicho, los medios que posibilitan la vida humana como fundamentos y condición de posibilidad de toda praxis, porque la vida humana está en peligro. 